\title{
Extinction Requires New RNA and Protein Synthesis and the Soma of the Cell Right Pedal Dorsal 1 in Lymnaea stagnalis
}

\author{
Susan Sangha, Andi Scheibenstock, Ross Morrow, and Ken Lukowiak \\ Department of Physiology and Biophysics, Calgary Brain Institute, University of Calgary, Calgary, Alberta, T2N 4N1 Canada
}

\begin{abstract}
Lymnaea stagnalis were operantly conditioned to not perform aerial respiratory behavior. This learned response was subsequently extinguished. Here, we show that spaced extinction training is more effective than massed extinction training, in addition to the occurrence of spontaneous recovery. We also find evidence of a critical period within the first hour after extinction training in which new RNA and protein synthesis must occur for a memory of extinction training to be established. The memory for extinction training can also be extended using cooling and by preventing aerial respiration from occurring after extinction training. In addition, we demonstrate that memory formation of extinction training requires the soma of the cell right pedal dorsal 1 , a cell that we have previously shown to be necessary for long-term memory consolidation and reconsolidation. This finding implies that the events that lead to the formation of extinction memory occur in the same cell that is responsible for long-term memory of operant conditioning. All of these data are consistent with the hypothesis that, during extinction, a new associative memory is being formed and that this new memory covers up, but does not abolish, the "old" memory.
\end{abstract}

Key words: Lymnaea; extinction; learning; memory; operant conditioning; protein synthesis

\section{Introduction}

The study of extinction dates back over 75 years, however, the study of the cellular mechanisms underlying it is still in its infancy. The mechanistic details of extinction are of great interest to researchers because extinction is used as a therapeutic tool in the treatment of fear disorders and substance addiction in humans. Advances in the understanding of the underlying mechanisms of extinction will make clinical protocols more effective.

Extinction is ubiquitous across paradigms (appetitive and aversive) and species (Caenorhabditis elegans to humans) (Myers and Davis, 2002). Several studies (Flood et al., 1977; Berman and Dudai, 2001; Vianna et al., 2001, 2003), although not all (Lattal and Abel, 2001), have demonstrated that extinction requires new protein synthesis. These data support the view that, during extinction training, new learning occurs and that there is a critical period in which protein synthesis is required for the induction of extinction memory. However, despite many efforts, no one brain structure has emerged that has a putative role in extinction that has not been met with substantial empirical challenges (Davis and Myers, 2002). We, in contrast, have the opportunity to study the changes underlying operant conditioning and the extinction of this memory at the level of a single cell in the model system Lymnaea stagnalis (for review, see Lukowiak et al., 2003).

Received June 23, 2003; revised Sept. 10, 2003; accepted Sept. 12, 2003.

This work was supported by a grant from the Canadian Institute of Health Research to K.L. S.S. was supported by a scholarship from the Natural Sciences and Engineering Research Council (Canada), and R.M. was supported by the Alberta Foundation for Medical Research High School Summer Studentship Program. We thank the reviewers for helpful comments.

Correspondence should be addressed to Dr. Ken Lukowiak, Department of Physiology and Biophysics, Calgary Brain Institute, University of Calgary, 3330 Hospital Drive NW, Calgary, Alberta, T2N 4N1 Canada. E-mail: lukowiak@ucalgary.ca.

Copyright $\odot 2003$ Society for Neuroscience $\quad 0270-6474 / 03 / 239842-10 \$ 15.00 / 0$
Because Lymnaea are bimodal breathers, it is possible to modulate one of its respiratory behaviors while leaving the other unaffected. More specifically, we used a nondeclarative, operant (i.e., instrumental) conditioning paradigm to decrease the occurrence of aerial respiratory behavior (Lukowiak et al., 1996, 1998, 2000). These snails can still breathe cutaneously, and, thus, our procedure is not harmful to the animals. A three-neuron central pattern generator (CPG), the sufficiency and necessity of which have been demonstrated (Syed et al., 1990, 1992), drives aerial respiration. In using this operant conditioning paradigm, neural correlates of learning and memory have been found in one of the three CPG neurons, the right pedal dorsal 1 (RPeD1) (Spencer et al., 1999, 2002), and RPeD1 is a site of long-term memory (LTM) formation (Scheibenstock et al., 2002) and memory reconsolidation (Sangha et al., 2003c).

Extinction in Lymnaea is context specific (McComb et al., 2002), and it is more difficult to induce in partially reinforced animals (partial reinforcement extinction effect) (Sangha et al., 2002). Here, we show the first demonstration of spontaneous recovery in Lymnaea and that spaced extinction training is more effective than massed extinction training. The demonstration that cooling, an RNA synthesis blocker, and a protein synthesis blocker can interfere with the formation of a memory for extinction training is also shown. Furthermore, by ablating the soma of a single cell (RPeD1) before extinction training, we prevent the occurrence of extinction. Conversely, the memory for extinction training can be extended using cooling and by preventing aerial respiration from occurring after training. All of these data are consistent with the hypothesis that, during extinction, a new associative memory is being formed and that this new memory covers up, but does not abolish, the "old" memory. 


\section{Materials and Methods}

Subjects. L. stagnalis were bred and raised in the snail facility at the University of Calgary. All snails used $(2.5-3.0 \mathrm{~cm})$ were maintained at room temperature $\left(23^{\circ} \mathrm{C}\right)$ and had ad libitum access to lettuce in their home eumoxic (i.e., normal levels of $\mathrm{O}_{2} ; 6 \mathrm{ml}$ of $\mathrm{O}_{2}$ /liter) aquaria.

Operant conditioning and extinction procedure. Individually labeled snails were placed in a 1 liter beaker containing $500 \mathrm{ml}$ of room temperature hypoxic $\left(<0.1 \mathrm{ml}\right.$ of $\mathrm{O}_{2} /$ liter $)$ water. The water was made hypoxic by bubbling $\mathrm{N}_{2}$ through it $20 \mathrm{~min}$ before and during training and testing. We refer to this as the "standard" hypoxic training procedure. We also use a "change of context" testing procedure (see Fig. $8 \mathrm{~B}$ ). To create the "different context," $\mathrm{N}_{2}$ was first bubbled through a $750 \mathrm{ml}$ Erlenmeyer flask with chopped carrots and water before being bubbled into the training beaker (Haney and Lukowiak, 2001). When sensing the presence of carrot odor, the animals perceived this as a different context and responded as if they had not received training (i.e., there is an increase in the number of pneumostome openings). The term "change of context test" means that snails were tested in the context that they were not trained in. This test is used as a control to show that after a given procedure snails are still as responsive as they were in the initial training session.

In all of the training sessions and tests for savings, a gentle tactile stimulus (using a sharpened wooden applicator) was applied to the pneumostome area (the respiratory orifice) every time the snail began to open its pneumostome to perform aerial respiration. This tactile stimulus only evoked pneumostome closure; it did not cause the animal to withdraw its foot and mantle area (i.e., the whole-animal withdrawal response). Pneumostome stimulation also did not cause the snails to sink to the bottom of the beaker. The time of each attempted opening was recorded and tabulated. In all experiments, the snails were first given a 10 min acclimatization period, where they could perform aerial respiration without receiving reinforcement. The onset of operant conditioning training was initiated by gently pushing the snails beneath the water surface. Between the training sessions and between the training sessions and the test for savings, as in all our previous experiments, snails were placed in eumoxic pond water where they were allowed to freely perform aerial respiration. We did not monitor the snails' breathing behavior during the periods they were in their eumoxic home aquaria.

During the extinction sessions, snails were placed in the same 1 liter beaker containing $500 \mathrm{ml}$ of room temperature hypoxic water. However, in these sessions, the reinforcing stimulus (tactile stimulus to the pneumostome area) was not applied in response to a pneumostome opening.

Specific protocol. In all experiments (with the exception of data shown in Figs. 7B, 8; see Results), snails were first administered three $45 \mathrm{~min}$ operant conditioning sessions. The first two training sessions were given on the same day $1 \mathrm{hr}$ apart. The following day, the third training session was given. This particular training regimen produces a memory that lasts $5 \mathrm{~d}$ (McComb et al., 2002). One hour after the last operant conditioning training session, extinction training began. This consisted of three $45 \mathrm{~min}$ sessions (no reinforcement applied): the first two were conducted on the same day $1 \mathrm{hr}$ apart, followed by the third session the next day (with the exception data shown in Figs. 1, 3, 8; see Results). A test for savings was administered $2 \mathrm{hr}$ after extinction training, unless otherwise specified (see Figs. 3, 5, 8; see Results).

Operational definitions of learning, memory, and extinction. We have operationally defined memory as we have previously (Lukowiak et al., 1996, 1998, 2000; Spencer et al., 1999, 2002). Learning was present if the number of attempted pneumostome openings in the last training session was significantly less than the number of attempted openings in the first training session. To be defined as memory, two criteria had to be met: (1) the number of pneumostome openings in the test for savings was significantly lower than that of the first training session; and (2) the number of pneumostome openings in the test for savings was not significantly higher than that of the last training session.

If these criteria were not met after extinction training, the behavior exhibited by the snails in the test for savings was not designated as memory for operant conditioning but instead classified as memory for extinction training.

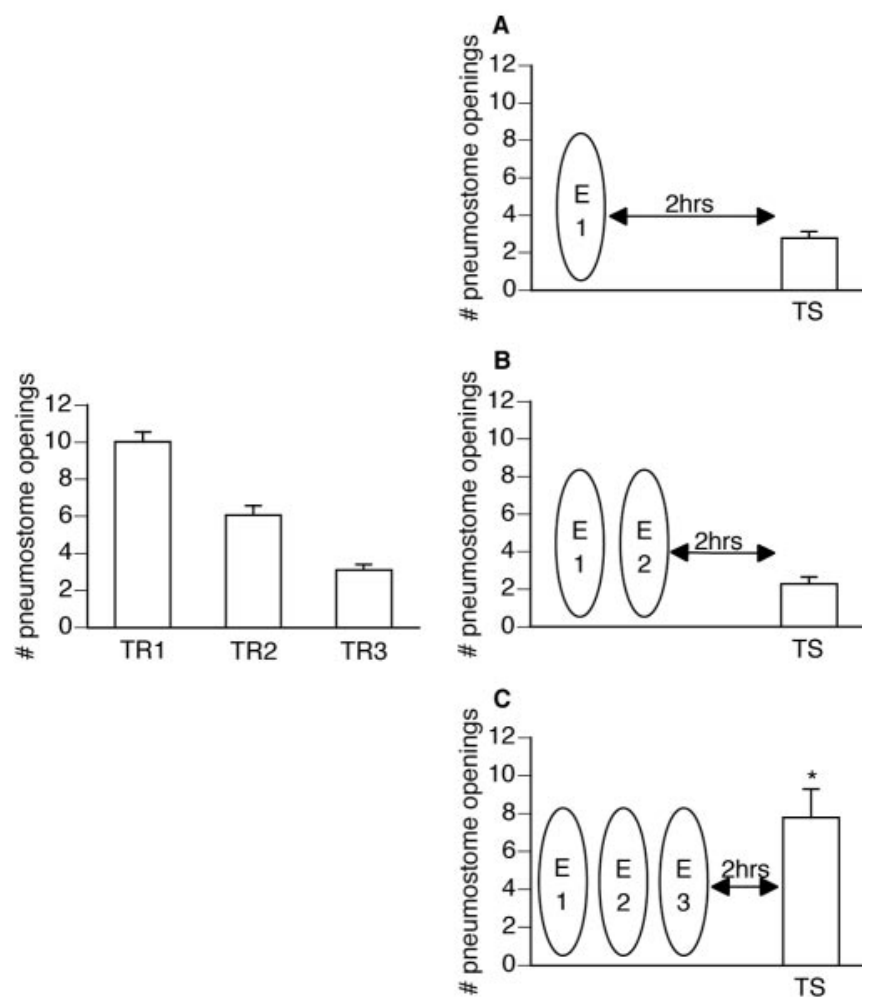

Figure 1. Three extinction sessions are needed for successful extinction. Forty-two animals received three 45 min training sessions (TR1 and TR2 were administered on the same day $1 \mathrm{hr}$ apart, followed by TR3, which was given the next day). Animals were then randomly divided into three groups ( $n=14$ each). Only animals that received three extinction sessions demonstrated memory for extinction at the $2 \mathrm{hr}$ test for savings (ANOVA; $F_{(41,4)}=74.5208 ; p<$ 0.0001 ). $A$, The first group received one 45 min extinction session (E1) $1 \mathrm{hr}$ after TR3 and then received a test for savings (TS) $2 \mathrm{hr}$ later. These animals did not show extinction but instead still demonstrated memory for operant conditioning: TS was significantly lower than TR1 ( $p<$ 0.01 ) and not significantly different than TR3 $(p>0.05) . B$, The second group received two 45 min extinction sessions (E1, E2) $1 \mathrm{hr}$ after TR3, each separated by $1 \mathrm{hr}$. A test for savings (TS) $2 \mathrm{hr}$ after E2 revealed memory for operant conditioning and not for the extinction training. TS was significantly lower than TR1 $(p<0.01)$ and not significantly different than TR3 $(p>0.05)$.C, The third group received three 45 min extinction sessions (E1, E2, E3) beginning $1 \mathrm{hr}$ after TR3, each separated by $1 \mathrm{hr}$. The test for savings (TS) $2 \mathrm{hr}$ after E3 revealed memory for the extinction training and not for operant conditioning. TS was significantly different $(p<0.01)$ from both TR1 and TR3, thus not meeting both criteria for operant memory designation.

Statistical analysis. To determine whether the experimental manipulation had an effect when compared with the control group and whether the number of attempted pneumostome openings was significantly altered as a result of operant conditioning or extinction training, we performed repeated measures one-way ANOVAs, testing both a betweengroup factor (i.e., control vs experimental) and a within-group factor (i.e., training sessions vs tests for savings) (Zar, 1999). If the ANOVA was significant $(p<0.05)$, either a post hoc Fisher's least significant difference (LSD) $t$ test or, when more appropriate, a Scheffé's comparison was performed to show which groups and sessions were significantly different (Glass and Hopkins, 1996). Differences were considered to be significant if $p<0.05$.

Cooling procedure. A 1 liter beaker filled with $500 \mathrm{ml}$ of eumoxic water was prechilled and maintained at $4^{\circ} \mathrm{C}$ and served as the cooling apparatus. Snails were kept in the cooling apparatus for $1 \mathrm{hr}$ (see Fig. 4) or $22 \mathrm{hr}$ (see Fig. 5). Afterward, snails were removed from the cooling apparatus and immediately placed in room temperature $\left(23^{\circ} \mathrm{C}\right)$ eumoxic water until the time of testing. We have shown previously that the cooling procedure does not adversely affect the snails (Sangha et al., 2003b). Breathing behavior was monitored before and after $8 \mathrm{~d}$ of cooling. The amount of time spent breathing in the precooling session was not significantly different than that in the postcooling session. Also, cooling can 
either block or extend the memory for operant conditioning depending on when it is applied (i.e., during or after memory consolidation, respectively) (Sangha et al., 2003b).

Submersion procedure. A eumoxic aquarium containing a plastic barrier served as the submersion apparatus. Snails were placed beneath the barrier, which prevented them from reaching the surface of the water and performing aerial respiration. The barrier had small holes in it, so that air bubbles could not accumulate on its undersurface. Atmospheric air, to create eumoxia, was continuously bubbled while the snails were maintained under the barrier. Snails had ad libitum access to food (lettuce) during the intervals between training and testing. Snails placed beneath the barrier were never observed to escape nor were they observed to perform aerial respiratory behavior. We have shown previously that this procedure does not adversely affect the snails and can extend the memory for operant conditioning (Sangha et al., 2003a). Aerial respiratory behavior was monitored before and after snails were submerged underneath a barrier for $3 \mathrm{~d}$. The number of pneumostome openings before submersion was not significantly different than after submersion.

Injections with RNA and protein synthesis blockers. The RNA synthesis blocker (dissolved in saline), protein synthesis blocker (dissolved in saline), or saline control was injected into the hemocoel through the foot of the animal. The concentrations used were $1 \mu \mathrm{g}$ of actinomycin D (RNA synthesis blocker) per milliliter of snail volume and $12.5 \mu \mathrm{g}$ of anisomycin (protein synthesis blocker) per milliliter of snail volume. These same concentrations were effectively used previously in our laboratory to block the transcription and translation processes, respectively (Feng et al., 1997; van Minnen et al., 1997; Hamakawa et al., 1999). We have also directly demonstrated that each of these blockers inhibits protein synthesis (Feng et al., 1997; van Minnen et al., 1997). As well, we have used these particular blockers in differentially affecting either intermediate-term memory (ITM) or LTM (Sangha et al., 2003d).

We have shown previously that these concentrations of protein synthesis blockers were effective when injected in the whole animal. We recalculated the concentrations to an amount of $0.1 \mathrm{ml}$ to be injected in snails with volumes of $3 \mathrm{ml}$. Additionally, we demonstrated previously that animals injected with actinomycin D did not show signs of sickness until $8 \mathrm{hr}$ after injection and anisomycin-injected animals did not show signs of sickness at any of the time points tested (2.5, 4.5, 8, and $24 \mathrm{hr}$ after injection) (Sangha et al., 2003d). The amount of time spent breathing and the number of pneumostome openings were monitored in noninjected, saline-injected, actinomycin D-injected, and anisomycin-injected animals at 2.5, 4.5, 8, and $24 \mathrm{hr}$ after injection. Injection of anisomycin did not affect these measurements at any of the time points. Injection of actinomycin D, however, did significantly alter respiratory behavior beyond $8 \mathrm{hr}$ after injection. All of the tests for savings performed in this study were within this time window (i.e., $8 \mathrm{hr}$ after injection).

Soma ablation procedure. We have shown previously that the soma of $\mathrm{RPeD} 1$ is required for LTM formation (Scheibenstock et al., 2002). The ablation procedure here was performed in the same manner as before. The ablation involved anesthetizing the animals with $1-3 \mathrm{ml}$ of $50 \mathrm{~mm}$ $\mathrm{MgCl}_{2}$ that was injected through the foot. This paralyzed the snail, allowing a dorsal midline incision to be made that exposed the animal's brain. Using a fine glass hand-held microelectrode, the RPeD1 soma was ablated by gently "poking" it. In control experiments, the soma of the left pedal dorsal 1 (LPeD1), which is similar in size to RPeD1 but does not play a role in aerial respiratory behavior, was ablated. The incision was small enough to allow the animal to heal without suturing. Animals began to wake from the effects of the anesthetic within several hours of the surgery.

To ensure that the proper soma of the cell had indeed been ablated, a trained individual who was unfamiliar with the experiments attempted to visualize the cells that were ablated under the microscope at the conclusion of the experiment. In all cases, the cell that had been ablated could not be found. We have shown previously that this procedure does not adversely affect the snails (Scheibenstock et al., 2002; Sangha et al., 2003c). The total breathing time and the number of pneumostome openings were monitored before and after RPeD1 soma ablation. There were no significant differences between preablation and postablation in either measurement.

\section{Results}

\section{Demonstrating extinction and spontaneous recovery}

Number of sessions (Fig. 1)

In this experiment, we demonstrated that with the particular operant conditioning training protocol used here (three $45 \mathrm{~min}$ sessions) a minimum of three 45 min extinction sessions must be used to ensure successful extinction. Snails $(n=42)$ were conditioned operantly according to the protocol outlined in Materials and Methods. One hour later, animals were given one $(n=14)$, two $(n=14)$, or three $(n=14) 45$ min extinction sessions, respectively, each separated by $1 \mathrm{hr}$. All animals were tested $2 \mathrm{hr}$ after extinction training. We waited only $2 \mathrm{hr}$ regardless of how many sessions were administered because, if extinction is induced by any of these protocols, the greatest likelihood of seeing extinction would be at $2 \mathrm{hr}$ after extinction training. A repeated measures one-way ANOVA was performed testing both a between-group factor (i.e., one vs two vs three extinction sessions) and a within-group factor (i.e., training sessions vs tests for savings). The ANOVA was significant $\left(F_{(41,4)}=74.5208 ; p<\right.$ 0.0001 ), and, thus, a post hoc Scheffé's comparison was performed to show which groups and sessions were significantly different. Only animals that received three extinction sessions demonstrated extinction during the test for savings. The test for savings for animals that received either one or two extinction sessions (Fig. 1, $A$ and $B$, respectively) was significantly lower $(p<0.01)$ than the test for savings for animals that received three extinction sessions (Fig. 1C). Furthermore, the test for savings for animals that received either one or two extinction sessions was significantly lower $(p<0.01)$ than the first training session and not significantly different $(p>0.05)$ than the third training session, thus meeting both criteria for memory of operant conditioning (i.e., no extinction). The test for savings for animals that received three extinction sessions (Fig. $1 C$ ) was significantly different $(p<0.01)$ from both the first and last training sessions, thus not meeting the criteria for memory of operant conditioning but of extinction training.

\section{Spontaneous recovery (Fig. 2)}

Spontaneous recovery was first demonstrated by Pavlov (1927) and has since been repeated in several studies of extinction. However, it has yet to be observed in Lymnaea, and thus, it is demonstrated in the following experiment. Snails $(n=26)$ were conditioned operantly and subsequently received extinction training (see Materials and Methods). Half the animals $(n=14)$ received a test for savings $2 \mathrm{hr}$ later as well as a $24 \mathrm{hr}$ savings test. The remaining animals $(n=12)$ received only the $24 \mathrm{hr}$ savings test. A repeated measures one-way ANOVA was performed testing both a between-group factor (i.e., administration of a 2 and $24 \mathrm{hr}$ test for savings vs administration of only a $24 \mathrm{hr}$ test for savings) and a within-group factor (i.e., training sessions vs tests for savings). The ANOVA was significant $\left(F_{(25,4)}=30.0463 ; p<0.0001\right)$, and, thus, a post hoc Scheffé's comparison was performed to show which groups and sessions were significantly different. The first group (Fig. $2 \mathrm{~A}$ ) showed extinction at $2 \mathrm{hr}$ [test for savings (TS1) was significantly different $(p<0.01)$ from both the first and last training sessions] and spontaneous recovery at $24 \mathrm{hr}$ [test for savings (TS2) was significantly lower $(p<0.01)$ than the first training session and not significantly different $(p>0.05)$ than the last training session]. Because the memory test at $2 \mathrm{hr}$ could be considered another training session because of the reinforcing stimulus being present and because it may explain why memory for operant conditioning was seen at $24 \mathrm{hr}$, the remaining animals $(n=12$; Fig. $2 B$ ) received only the $24 \mathrm{hr}$ test for savings. These 


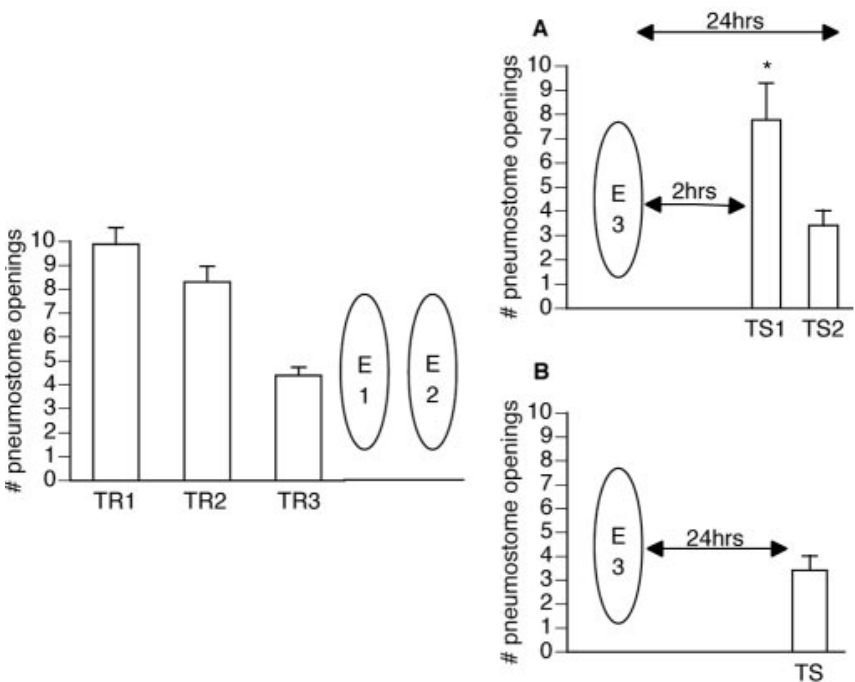

Figure 2. Demonstration of spontaneous recovery at $24 \mathrm{hr}$. Twenty-six animals received three 45 min training sessions (TR1 and TR2 were administered on the same day $1 \mathrm{hr}$ apart, followed by TR3, which was given the next day). One hour later, all animals then received three 45 min extinction sessions (E1 and E2 were administered on the same day $1 \mathrm{hr}$ apart, followed by E3, which was given the next day). Animals were then divided randomly into two groups. All animals demonstrated spontaneous recovery at $24 \mathrm{hr}$ whether or not they received a test for savings $2 \mathrm{hr}$ after extinction training (ANOVA; $\left.F_{(25,4)}=30.0463 ; p<0.0001\right) . A$, The first group ( $n=14$ ) received two tests for savings (TS1 and TS2): one at $2 \mathrm{hr}$ after E3 and one at $24 \mathrm{hr}$ after E3. Animals demonstrated memory for extinction training at $2 \mathrm{hr}$; TS1 was significantly different from both TR1 $(p<0.05)$ and TR3 $(p<0.01)$, thus not meeting the criteria for operant memory designation. At $24 \mathrm{hr}$, however, animals demonstrated spontaneous recovery for the memory for operant conditioning; TS2 was significantly lower than TR1 $(p<0.01)$ and not significantly different than TR3 $(p>0.05)$. B, The second group $(n=12)$ received only one test for savings (TS1), $24 \mathrm{hr}$ after E3. These animals demonstrated spontaneous recovery for the memory for operant conditioning; TS1 was significantly lower than TR1 $(p<0.01)$ and not significantly different than TR3 ( $p>0.05)$.

animals showed memory for operant conditioning and were indistinguishable [the $24 \mathrm{hr}$ test for savings in Fig. 2A was not significantly different $(p>0.05)$ from that in Fig. $2 B]$ from the animals that also received the $2 \mathrm{hr}$ test [test for savings was significantly lower $(p<0.01)$ than the first training session and not significantly different $(p>0.05)$ than the last training session]. Thus, animals that were tested at $2 \mathrm{hr}$ demonstrated extinction, and all animals showed spontaneous recovery of the memory for operant conditioning at $24 \mathrm{hr}$.

\section{Spaced extinction trials are more effective than massed}

It is often cited in the learning literature that a memory is more effectively induced after spaced training when compared with massed training (Lukowiak et al., 2000; Menzel et al., 2001). Demonstrating that extinction follows this same principle lends additional support to the notion that extinction is new learning. In the following experiment, snails received either spaced extinction training (three 45 min sessions each separated by $1 \mathrm{hr}$ ) or massed extinction training (one 135 min session that corresponds to three $45 \mathrm{~min}$ sessions) after operant conditioning training. Because the administration of spaced extinction training is longer than the massed training, we administered the massed extinction training trial at two time points [either $1 \mathrm{hr}$ (Fig. 3C,D) or $3 \mathrm{hr}$ (Fig. 3E) after operant training] as well as assessing memory for extinction training at two time points [either $2 \mathrm{hr}$ (Fig. 3C,E) or $4 \mathrm{hr}$ (Fig. 3D) after massed extinction training].

All snails $(n=83)$ were first operantly conditioned (the first
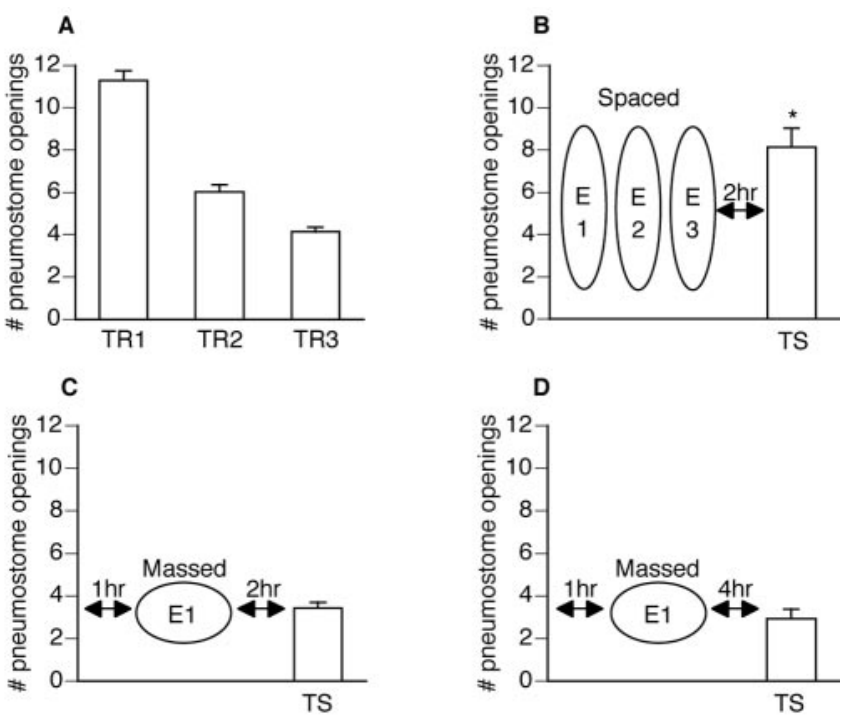

E



Figure 3. Spaced extinction training is more effective than massed extinction training. All animals were first operantly conditioned and subsequently received either spaced or massed extinction training. Only those animals that received the spaced extinction training demonstrated memory for extinction during the test for savings $\left(\operatorname{ANOVA}_{(82,5)}=127.4121 ; p<\right.$ $0.0001)$. A, All animals ( $n=83$ ) received three 45 min operant conditioning training sessions (TR1 and TR2 were administered on the same day $1 \mathrm{hr}$ apart, followed by TR3 the next day). Animals were then divided into four groups $(B-E)$. $B$, Animals $(n=28)$ received three $45 \mathrm{~min}$ extinction sessions (E1-E3), each separated by $1 \mathrm{hr}$, beginning $1 \mathrm{hr}$ after TR3 and tested $2 \mathrm{hr}$ after E3. The test for savings was significantly different $(p<0.01)$ from both TR1 and TR3, thus not meeting the criteria for operant memory designation. $C$, Animals $(n=28)$ received one 135 min extinction session beginning $1 \mathrm{hr}$ after TR3 and tested $2 \mathrm{hr}$ after E1. The test for savings was significantly lower $(p<0.01)$ than TR1 and not significantly different $(p>0.05)$ than TR3, thus meeting both criteria for operant memory designation. $D$, Animals $(n=14)$ received one 135 min extinction session beginning $1 \mathrm{hr}$ after TR3 and tested $4 \mathrm{hr}$ after E1. The test for savings was significantly lower $(p<0.01)$ than TR1 and not significantly different $(p>0.05)$ than TR3, thus meeting both criteria for operant memory designation. $E$, Animals $(n=13)$ received one 135 min extinction session beginning $3 \mathrm{hr}$ after TR3 and tested $2 \mathrm{hr}$ after E1. The test for savings was significantly lower $(p<0.01)$ than TR1 and not significantly different $(p>0.05)$ than TR3, thus meeting both criteria for operant memory designation.

two training sessions were administered on the same day $1 \mathrm{hr}$ apart, followed by a third training session the next day; Fig. $3 A$ ). Animals were then divided into four groups (Fig. $3 B-E$ ). Only the snails that received spaced extinction training demonstrated memory for extinction training during the test for savings (repeated measures one-way ANOVA; $F_{(82,5)}=127.4121 ; p<$ $0.0001)$. The test for savings for the group that received spaced extinction training (Fig. 3B) was significantly higher ( post hoc Scheffé's comparison; $p<0.01$ ) than the tests for savings for each of the groups that received massed extinction training (Fig. $3 C-E)$.

The first group ( $n=28$; Fig. $3 B$ ) received spaced extinction training: three 45 min extinction sessions (E1-E3), each separated by $1 \mathrm{hr}$, beginning $1 \mathrm{hr}$ after the third training session (TR3). The test for savings administered $2 \mathrm{hr}$ after E3 was signif- 


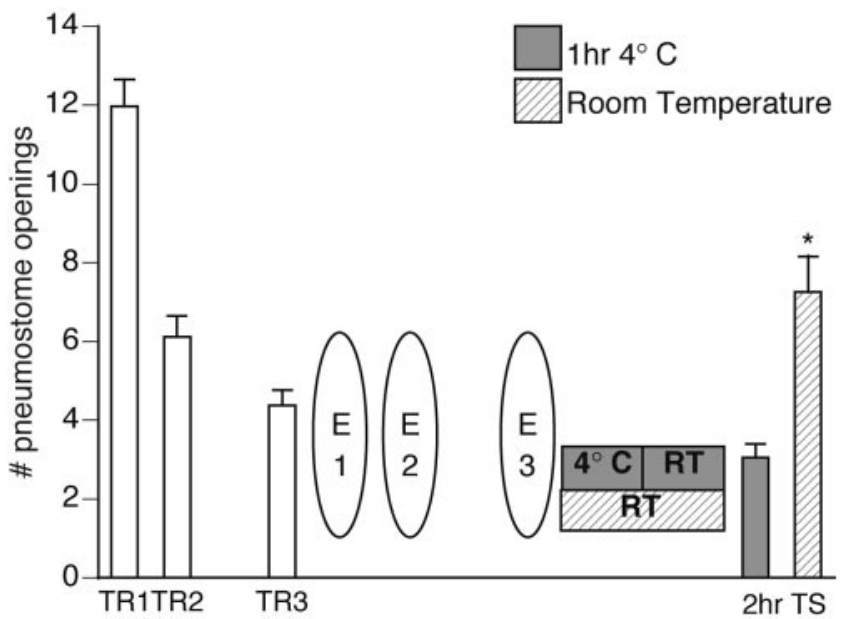

Figure 4. Cooling blocks memory formation for extinction training. Forty animals received three 45 min operant conditioning sessions (TR1 and TR2 were administered on the same day 1 hr apart, followed by TR3 on the next day). One hour later, animals received three $45 \mathrm{~min}$ extinction sessions (E1 and E2 were administered on the same day $1 \mathrm{hr}$ apart, followed by E3 the next day). Half the animals ( $n=20$ ) were maintained at room temperature (RT) whereas the other half $(n=20)$ of the animals were immediately placed in prechilled $4^{\circ} \mathrm{C}$ water for $1 \mathrm{hr}$ and then immediately transferred to room temperature water. All animals were tested for savings 2 $\mathrm{hr}$ after extinction training. The test for savings for animals kept at room temperature was significantly higher $(p<0.01)$ than the test for savings for animals that were first put in $4^{\circ} \mathrm{C}$ water for $1 \mathrm{hr}\left(\right.$ ANOVA; $\left.F_{(39,3)}=60.4611 ; p<0.0001\right)$. Animals maintained at room temperature demonstrated memory for extinction training; TS was significantly different ( $p<0.01$ ) from both TR1 and TR3, thus not meeting the criteria for operant memory designation. Animals that were placed in $4^{\circ} \mathrm{C}$ water for $1 \mathrm{hr}$ immediately after extinction training did not show memory for extinction training but instead demonstrated memory for operant conditioning. TS was significantly different $(p<0.01)$ than TR1 and not significantly different $(p>0.05)$ from TR3.

icantly different $(p<0.01)$ from both TR1 and TR3, thus not meeting the criteria for operant memory designation but of memory for extinction training. The second group $(n=28$; Fig. $3 C$ ) received one 135 min extinction session beginning $1 \mathrm{hr}$ after TR3 and tested $2 \mathrm{hr}$ after E1. The test for savings was significantly lower $(p<0.01)$ than TR1 and not significantly different $(p>$ 0.05 ) than TR3, thus meeting both criteria for operant memory designation. The third group $(n=14$; Fig. $3 D)$ received one 135 min extinction session beginning $1 \mathrm{hr}$ after TR3 and tested $4 \mathrm{hr}$ after E1. The test for savings was significantly lower $(p<0.01)$ than TR1 and not significantly different $(p>0.05)$ than TR3, thus meeting both criteria for operant memory designation. The last group $(n=13$; Fig. $3 E)$ received one 135 min extinction session beginning $3 \mathrm{hr}$ after TR3 and tested $2 \mathrm{hr}$ after E1. The test for savings was significantly lower $(p<0.01)$ than TR1 and not significantly different $(p>0.05)$ than TR3, thus meeting both criteria for operant memory designation. Thus, in all cases in which massed extinction training was administered, memory for extinction training was not observed during the test for savings. Therefore, we conclude that spaced extinction training is more effective than massed extinction training.

\section{Cooling can block memory formation for extinction training (Fig. 4)}

Cooling has been used in several laboratories as a tool to disrupt memory formation (Yamada et al., 1992; Cartford et al., 1997; Morrison and van der Kooy, 1997; Sekiguchi et al., 1997; Sangha et al., 2003b). If applied during the consolidation phase, it has been very successful in interfering with the cascade of events that lead to the formation of an ITM or LTM. We used this technique immediately after extinction training to see whether we could disrupt the consolidation of the memory for extinction training.

Snails $(n=40)$ were conditioned operantly and subsequently received spaced extinction training (see Materials and Methods). Immediately (within $30 \mathrm{sec}$ ) after the last extinction session, animals were either maintained at room temperature $(n=20)$ or were placed in prechilled $4^{\circ} \mathrm{C}$ water $(n=20)$ for $1 \mathrm{hr}$ before being put back in room temperature water and were tested $2 \mathrm{hr}$ after extinction training. A repeated measures one-way ANOVA was performed testing both a between-group factor (i.e., cooling vs room temperature control) and a within-group factor (i.e., training sessions vs tests for savings). The ANOVA was significant $\left(F_{(39,3)}=60.4611 ; p<0.0001\right)$, and, thus, a post hoc Scheffé's comparison was performed to show which groups and sessions were significantly different. The test for savings for animals that received $1 \mathrm{hr}$ of cooling was significantly lower $(p<0.01)$ than the test for savings for animals that remained in room temperature water. Furthermore, animals that received the $1 \mathrm{hr}$ of cooling immediately after extinction training did not demonstrate memory for extinction training but instead showed memory for operant conditioning. The test for savings was significantly lower $(p<0.01)$ than the first training session and not significantly different $(p>0.05)$ than the last training session. In contrast, the animals that were maintained at room temperature did show memory for extinction training. The test for savings was significantly different $(p<0.01)$ from both the first and last training sessions. Thus, cooling was effective in blocking the formation of memory for extinction training.

\section{The memory for extinction can be extended}

We have recently demonstrated that a memory for operant conditioning can be extended either by cooling the animals after the consolidation phase (Sangha et al., 2003b) or by preventing animals from performing aerial respiratory behavior via a submersion apparatus between the training and test sessions (Sangha et al., 2003a). These findings support the view that, during forgetting, the animal is learning something new. Cooling was able to extend the memory of both (i.e., prevent the forgetting of) operant conditioning and extinction, suggesting that forgetting requires protein synthesis. If extinction is simply a passive process, it should not be affected by these two techniques. However, cooling and submerging the animals would have a profound effect if extinction was an active process.

\section{Cooling can extend the memory for extinction training (Fig. 5)}

Animals $(n=26)$ were conditioned operantly and subsequently received spaced extinction training (see Materials and Methods). One hour after the last extinction session, all animals were placed in prechilled $4^{\circ} \mathrm{C}$ water for $22 \mathrm{hr}$, after which they were put back into room temperature water for $2 \mathrm{hr}$. A repeated measures oneway ANOVA was performed testing a within-group factor (i.e., training sessions vs tests for savings). The ANOVA was significant $\left(F_{(25,2)}=46.8073 ; p<0.0001\right)$, and, thus, a post hoc Fisher's LSD $t$ test was performed to show which sessions were significantly different. The test for savings reveal that these animals still exhibit memory for extinction training when they normally show spontaneous recovery for operant conditioning (Fig. 2). The test for savings was not significantly different $(p>0.05)$ than the first training session and was significantly higher $(p<0.01)$ than the last training session. Thus, cooling was successful in extending the memory for extinction training if applied $1 \mathrm{hr}$ after extinction training. 


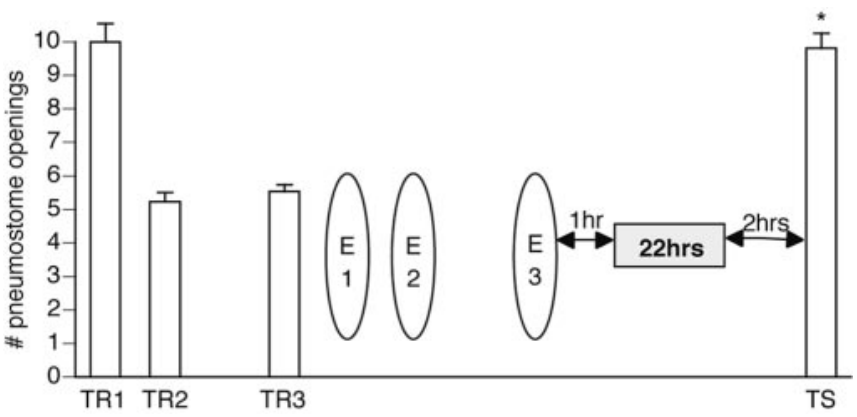

Figure 5. Cooling can extend the memory for extinction training. Twenty-six animals received three 45 min operant conditioning sessions (TR1 and TR2 were administered on the same day $1 \mathrm{hr}$ apart, followed by TR3 on the next day). One hour later, animals received three $45 \mathrm{~min}$ extinction sessions (E1 and E2 were administered on the same day $1 \mathrm{hr}$ apart, followed by E3 the next day). One hour later, all animals were immediately placed in prechilled $4^{\circ} \mathrm{C}$ water for $22 \mathrm{hr}$, after which they were transferred to room temperature water. Two hours later, animals were tested for savings. Animals still showed memory for extinction training when they normally demonstrate spontaneous recovery for operant conditioning (Fig. 2). TS was not significantly different $(p>0.05)$ from TR1 and was significantly higher $(p<0.01)$ than TR3, thus not meeting the criteria for operant memory designation. $\left(\operatorname{ANOVA} ; F_{(25,2)}=46.8073 ; p<0.001\right)$.

Preventing aerial respiration can extend the memory for extinction training (Fig. 6)

Snails $(n=42)$ were conditioned operantly and subsequently received spaced extinction training (see Materials and Methods). After the last extinction session, animals were divided into three groups ( $n=14$ each): (1) 2 and $24 \mathrm{hr}$ tests for savings-no submersion; (2) 2 and 24 hr tests for savings-submerged immediately (within $30 \mathrm{sec}$ ) after extinction training; and (3) $24 \mathrm{hr}$ test for savings-submerged immediately after extinction training. A repeated measures one-way ANOVA was performed testing both a between-group factor (i.e., group I vs group II vs group III) and a within-group factor (i.e., training sessions vs tests for savings). The ANOVA was significant $\left(F_{(41,6)}=36.8938 ; p<0.0001\right)$, and, thus, a post hoc Scheffe's comparison was performed to show which groups and sessions were significantly different. The $24 \mathrm{hr}$ test for savings (TS2; Fig. 6A) for animals that were not submerged (group I) was significantly lower than the $24 \mathrm{hr}$ test for savings for animals that were submerged [groups II (TS2; Fig. 6B) and group III (TS; Fig. 6C); $p<0.01$ ].

Group I (Fig. $6 A$ ) was not submerged after extinction training and received two tests for savings: 2 and $24 \mathrm{hr}$ postextinction training (as in Fig. 2A). Memory for extinction was seen at the 2 hr test [test for savings (TS1) was significantly different $(p<$ 0.01 ) than both the first and last training sessions] whereas spontaneous recovery was seen at the $24 \mathrm{hr}$ test [test for savings (TS2) was significantly lower $(p<0.01)$ than the first training session and not significantly different $(p>0.05)$ than the last training session]. The two remaining groups were placed in the submersion apparatus immediately after extinction training. One group (Fig. $6 \mathrm{~B}$ ) was removed from the submersion apparatus to administer a $2 \mathrm{hr}$ and a $24 \mathrm{hr}$ extinction training test for savings. The last group (Fig. $6 \mathrm{C}$ ) was removed at the $24 \mathrm{hr}$ time point only to administer a test for savings. By submerging the animals after extinction training, we are preventing them from performing aerial respiration, because they cannot reach the air-water interface. If the animal cannot open its pneumostome, then it cannot establish any new associations regarding this behavior. Using this procedure, we have demonstrated previously that the memory for operant conditioning can be extended (Sangha et al., 2003a). Here, we asked whether the same procedure could extend the memory for extinction training in a similar manner, and, indeed,
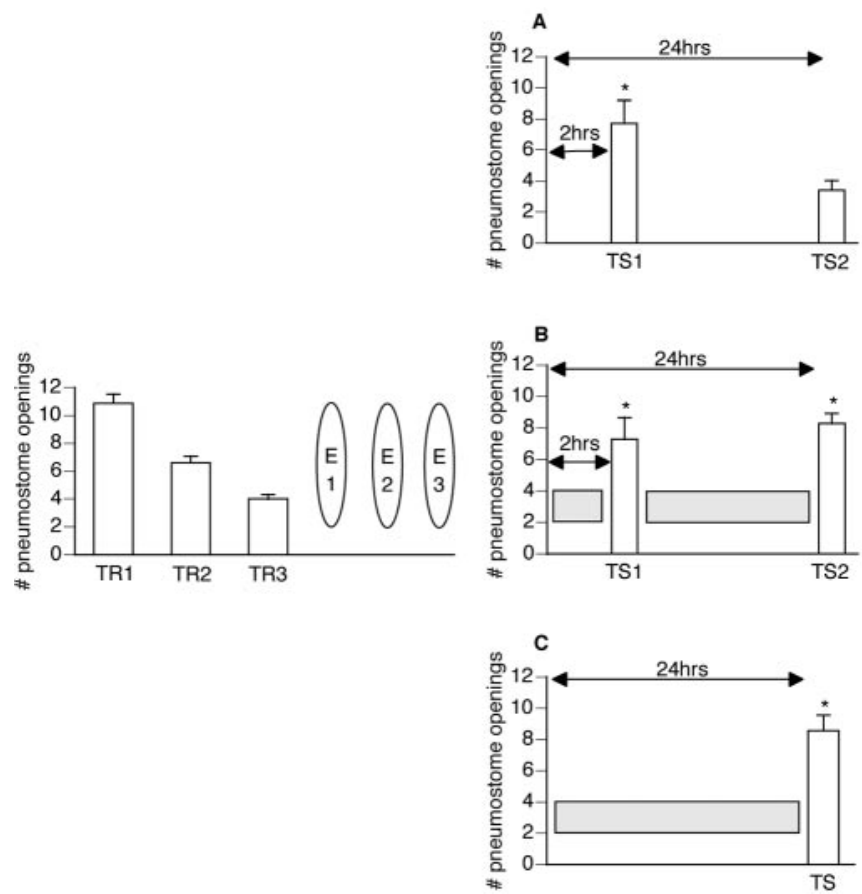

Figure 6. Submersion can extend the memory for extinction training. Forty-two animals received three 45 min operant conditioning sessions (TR1 and TR2 were administered on the same day $1 \mathrm{hr}$ apart, followed by TR3 the next day). One hour later, animals received three 45 min extinction sessions (E1 and E2 were administered on the same day $1 \mathrm{hr}$ apart, followed by E3 the next day). The animals were then divided into three groups ( $n=14$ each). $A$, The first group received two tests for savings (TS1 and TS2): one at $2 \mathrm{hr}$ after E3 and one at $24 \mathrm{hr}$ after E3. Memory for extinction training was demonstrated at TS1; TS1 was significantly different ( $p<$ 0.01) from both TR1 and TR3, thus not meeting the criteria for operant memory designation. Spontaneous recovery for the memory of operant conditioning was demonstrated at TS2; TS2 was significantly lower $(p<0.01)$ than TR1 and not significantly different $(p>0.05)$ from TR3, thus meeting the criteria for operant memory designation. $B$, The second group was immediately submerged after $\mathrm{E} 3$ and only taken out for the two tests for savings: one at $2 \mathrm{hr}$ after E3 and one at $24 \mathrm{hr}$ after E3. Memory for extinction training was demonstrated at both tests for savings; TS1 and TS2 were both significantly different $(p<0.01)$ from both TR1 and TR3, thus not meeting the criteria for operant memory designation. $C$, The third group was submerged immediately after $\mathrm{E} 3$ and only taken out for a test for savings at $24 \mathrm{hr}$ after E3. These animals demonstrated memory for extinction training; TS was significantly different $(p<0.01)$ from both TR1 and TR3, thus not meeting the criteria for operant memory designation (ANOVA; $\left.F_{(41,6)}=36.8938 ; p<0.0001\right)$.

it did. Animals normally exhibit spontaneous recovery $24 \mathrm{hr}$ after extinction training (Figs. 2, 6A). If animals are submerged immediately after extinction training, the memory for extinction training can be extended to at least $24 \mathrm{hr}$ (Fig. 6B,C) [all tests for savings were significantly different $(p<0.01)$ than both the first and last training sessions]. Thus, preventing aerial respiration can extend the memory for extinction training.

\section{Extinction requires new protein and RNA synthesis (Fig. 7)}

Several laboratories have shown the need for new protein and RNA synthesis in the formation of new LTMs (Davis and Squire, 1984; Rosenzweig et al., 1993; McGaugh, 2000; Sangha et al., 2003d). Here, the commonly used RNA synthesis blocker actinomycin D and protein synthesis blocker anisomycin were systemically injected into the snail immediately after extinction training.

Snails ( $n=75$; Fig. $7 A$ ) were conditioned operantly and subsequently received extinction training (see Materials and Methods). Immediately after the last extinction session, animals received a saline $(n=26)$, actinomycin $\mathrm{D}(n=28)$, or anisomycin $(n=21)$ injection, respectively. All animals were tested for sav- 
A

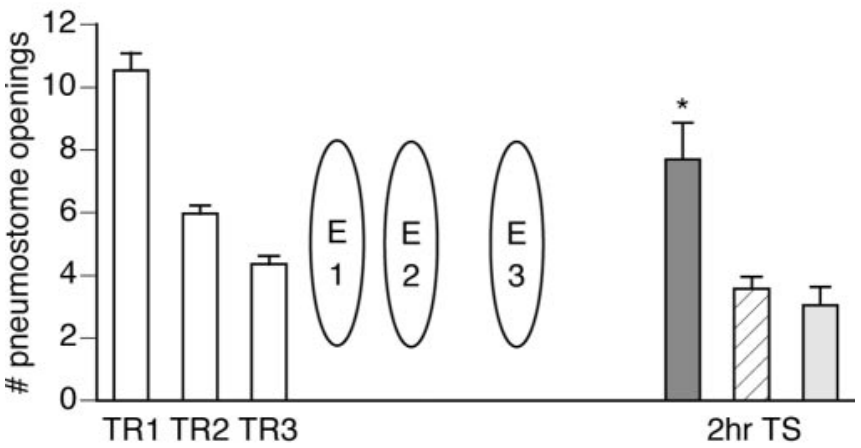

B

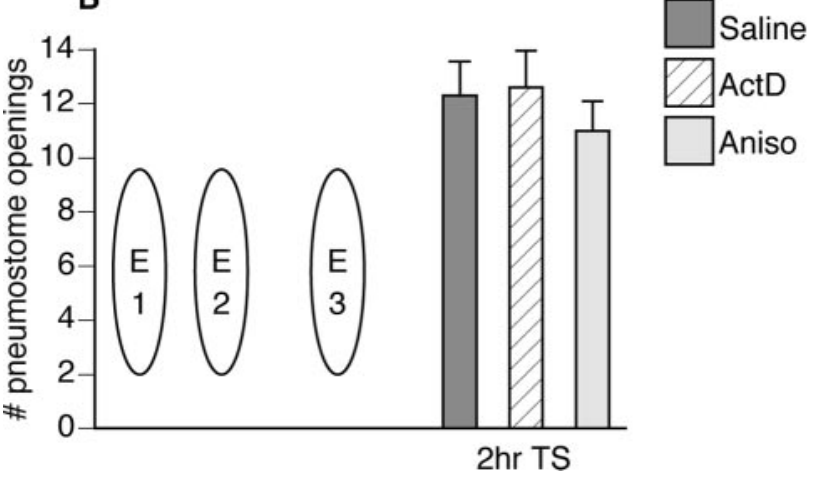

Figure 7. Protein and RNA synthesis are required to form a memory for extinction training. $A$, Seventy-five animals received three 45 min operant conditioning sessions (TR1 and TR2 were administered on the same day $1 \mathrm{hr}$ apart, followed by TR3 the next day). One hour later, animals received three 45 min extinction sessions (E1 and E2 were administered on the same day $1 \mathrm{hr}$ apart, followed by $E 3$ the next day). Immediately after $E 3$, animals were injected with either saline $(n=26)$, actinomycin $D(n=28)$, or anisomycin $(n=21)$. Two hours later, a test for savings was administered to all animals. Only the animals injected with saline showed memory for extinction training (ANOVA; $\left.F_{(74,4)}=80.9878 ; p<0.0001\right)$; TS was significantly different $(p<0.01)$ from both TR1 and TR3, thus not meeting the criteria for operant memory designation. Animals injected with either actinomycin $D$ or anisomycin still showed memory for operant conditioning; TS for both groups was significantly lower $(p<0.01)$ than TR1 and not significantly different $(p>0.05)$ than TR3. $B$, Thirty animals received three 45 min extinction sessions ( $E 1$ and E2 were administered on the same day $1 \mathrm{hr}$ apart, followed by E3 the next day) without any prior operant conditioning. Immediately after E3, animals were injected with either saline $(n=10)$, actinomycin $\mathrm{D}(n=10)$, or anisomycin $(n=10)$. Two hours later, a test for savings was administered to all animals. There were no differences $(p>0.05)$ between the three injected groups.

ings $2 \mathrm{hr}$ later. A repeated measures one-way ANOVA was performed testing both a between-group factor (i.e., saline vs actinomycin D vs anisomycin) and a within-group factor (i.e., training sessions vs tests for savings). The ANOVA was significant $\left(F_{(74,4)}=80.9878 ; p<0.0001\right)$, and, thus, a post hoc Scheffé's comparison was performed to show which groups and sessions were significantly different. The test for savings for the saline group was significantly higher than that for the actinomycin $\mathrm{D}$ group $(p<0.01)$ and the anisomycin group $(p<0.01)$. Furthermore, when tested for savings $2 \mathrm{hr}$ later, only the saline group demonstrated memory for extinction, whereas both the actinomycin D and anisomycin groups still showed memory for operant conditioning. The test for savings in the saline group was significantly different from both the first and last training sessions, thus demonstrating memory for extinction training. The tests for savings in the actinomycin $\mathrm{D}$ and anisomycin groups were both significantly lower $(p<0.01)$ than the first training session and not significantly different $(p>0.05)$ than the last training session. Thus, both the RNA synthesis blocker (actinomycin D) and the protein synthesis blocker (anisomycin) blocked the formation of the memory for extinction training.

It is possible that the animals injected with actinomycin $\mathrm{D}$ and anisomycin were sick at the time of testing, even though we have shown previously (Sangha et al., 2003d) that animals injected with these particular inhibitors exhibit normal aerial respiratory behavior within the time windows tested here. Thus, we administered three 45 min extinction sessions (E1 and E2 were administered on the same day $1 \mathrm{hr}$ apart, followed by $\mathrm{E} 3$ the next day) to 30 animals without any prior operant conditioning (Fig. 7B). Immediately after the last extinction session, animals were injected with saline $(n=10)$, actinomycin $\mathrm{D}(n=10)$, or anisomy$\operatorname{cin}(n=10)$. Two hours later, a test for savings was administered to all animals. There were no differences $(p>0.05)$ between the three injected groups, thus demonstrating that animals are capable of normal aerial respiratory behavior $2 \mathrm{hr}$ after injection.

\section{Extinction requires the soma of $\mathrm{RPeD1}$ (Fig. 8)}

We have shown previously that the soma of RPeD1 is necessary for the consolidation and formation of a new long-term nondeclarative memory (Scheibenstock et al., 2002). By ablating the soma of RPeD1, we removed the nucleus of this cell and, thus, inhibited RNA synthesis in RPeD1 specifically. Here, we investigated whether the soma of RPeD1 is necessary for the induction of a memory for extinction training.

Because the ablation procedure needed to be performed after operant conditioning but before extinction training, a modified training regimen was used. Snails $(n=33)$ received two $45 \mathrm{~min}$ operant conditioning sessions separated by $1 \mathrm{hr}$ (Fig. 8A). One hour later, animals underwent surgery in which either the soma of LPeD1 (control; $n=22)$ or RPeD1 $(n=11)$ was ablated. Two days later (to allow for full surgical recovery), extinction training was administered (two 45 min extinction training sessions separated by $1 \mathrm{hr}$ ). All animals were tested for savings $4 \mathrm{hr}$ after extinction training. A repeated measures one-way ANOVA was performed testing both a between-group factor (i.e., LPeD1 soma ablated vs RPeD1 soma ablated) and a within-group factor (i.e., training sessions vs tests for savings). The ANOVA was significant $\left(F_{(32,2)}=67.975 ; p<0.0001\right)$, and, thus, a post hoc Scheffé's comparison was performed to show which groups and sessions were significantly different. The test for savings for the LPeD1 soma-ablated group was significantly higher $(p<0.01)$ than that of the RPeD1 soma-ablated group. Furthermore, the LPeD1 soma-ablated savings test was significantly higher $(p<0.01)$ than the last training session and not significantly different $(p>$ 0.05 ) than the first training session, thus demonstrating memory for extinction training. The RPeD1 soma-ablated savings test, however, was not significantly different $(p>0.05)$ than the last training session and was significantly lower $(p<0.01)$ than the first training session, thus meeting both criteria for memory of operant conditioning. Thus, the LPeD1 soma-ablated animals demonstrated memory for extinction when tested $4 \mathrm{hr}$ later, whereas the RPeD1 soma-ablated animals still demonstrated memory for operant conditioning.

To demonstrate that a RPeD1 soma-ablated animal is indeed capable of accessing an already consolidated LTM (Scheibenstock et al., 2002), an additional 15 animals were conditioned operantly (Fig. $8 \mathrm{~B}$ ). One hour after training, the soma of RPeD1 was ablated in all animals. A test for savings was administered $2 \mathrm{~d}$ later in which animals demonstrated memory. A repeated measures oneway ANOVA was performed testing a within-group factor (i.e., training sessions vs tests for savings). The ANOVA was significant 
A

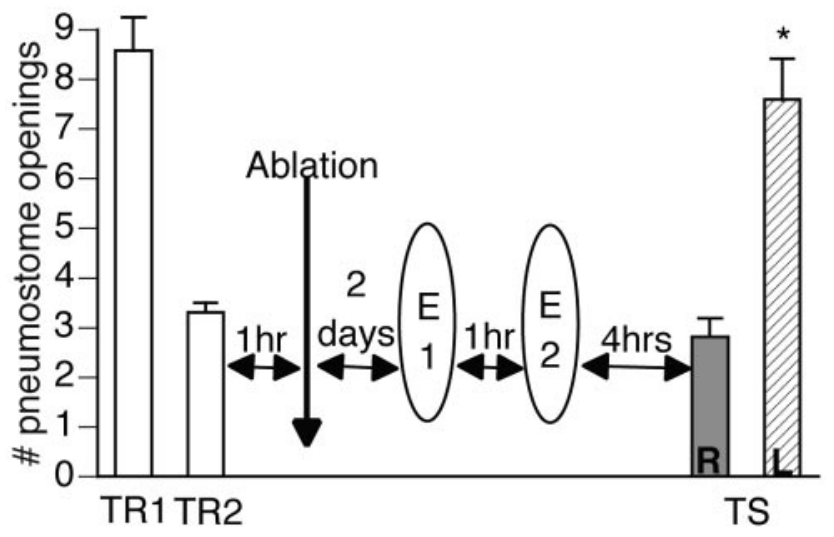

B

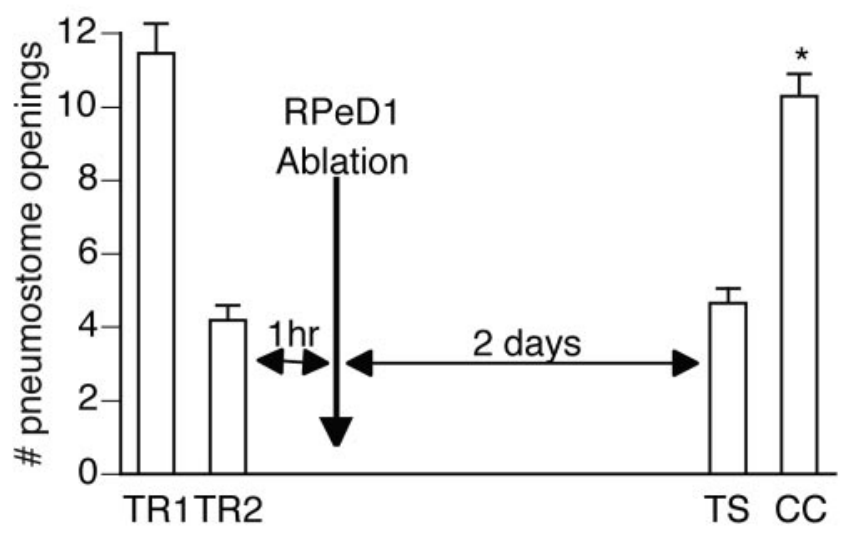

Figure 8. Extinction requires the soma of RPeD1. A, Thirty-three animals received two 45 min operant conditioning sessions separated by $1 \mathrm{hr}$. One hour later, animals underwent surgery in which the soma of either LPeD1 $(n=22)$ or RPeD1 $(n=11)$ was ablated. Two days later (to allow for surgical recovery), extinction training was administered: two 45 min extinction sessions separated by $1 \mathrm{hr}$. Four hours later, all animals were tested for savings. LPeD1 somaablated animals demonstrated memory for the extinction training; TS (L) was significantly different $(p<0.01)$ than the last training session but not significantly different $(p>0.05)$ from the first training session. RPeD1 soma-ablated animals did not demonstrate memory for extinction training but of operant conditioning; TS (R) was not significantly different ( $p>$ $0.05)$ from the last training session and was significantly lower $(p<0.01)$ than the first training session (ANOVA; $\left.F_{(32,2)}=67.975 ; p<0.0001\right)$. B, Fifteen animals received two $45 \mathrm{~min}$ operant conditioning sessions separated by $1 \mathrm{hr}$. One hour later, the soma of RPeD1 was ablated. A test for savings was administered $2 \mathrm{~d}$ later: TS was significantly lower $(p<0.01)$ than TR1 and not significantly different $(p>0.05)$ from TR2 (ANOVA; $F_{(14,2)}=67.1629 ; p<0.0001$ ). A change of context $(C C)$ test was administered to demonstrate that these animals are still capable of aerial respiratory behavior. CC was not significantly different $(p>0.05)$ from TR1 and was significantly higher $(p<0.01)$ than TR2.

$\left(F_{(14,2)}=67.1629 ; p<0.0001\right)$, and, thus, a post hoc Fisher's LSD $t$ test was performed to show which sessions were significantly different. The test for savings was significantly lower $(p<0.01)$ than the first training session and not significantly different than the last training session. A change of context test (see Materials and Methods) was subsequently administered to guarantee that these animals were not sick (Scheibenstock et al., 2002). The change of context test was significantly higher $(p<0.01)$ than both the last training session and the test for savings as well as being not significantly different $(p>0.05)$ than the first training session. Thus, ablation of this cell after operant training, in the absence of extinction, has no effect on operant responding.

\section{Discussion}

The study of extinction began with Pavlov (1927), who discovered that the conditioned salivary response of his dogs to a foodsignaling cue diminished and finally disappeared when the cue was repeatedly presented in the absence of food (Davis and Myers, 2002). Since then, it has been shown across different learning paradigms and in several invertebrate (Richards et al., 1984; Rankin, 2000; McComb et al., 2002; Schwaerzel et al., 2002) and vertebrate (for review, see Myers and Davis, 2002) model systems. However, the mechanistic details underlying extinction remain obscure.

An advantage in using Lymnaea in the study of extinction is that neural correlates of memory for an operant conditioning task have already been located in one particular cell, RPeD1 (Spencer et al., 1999, 2002). We have also previously shown that the presence of RPeD1 is required in the formation of new LTMs (Scheibenstock et al., 2002) and their reconsolidation (Sangha et al., 2003c). Here, we show that extinction in Lymnaea shares many principles with learning and remembering something new. In summary, we have demonstrated the presence of spontaneous recovery and that spaced extinction training is more effective than massed extinction training. Using several approaches, we have shown that extinction requires new protein and RNA synthesis and, by ablating the soma of one specific cell (RPeD1), we prevented the occurrence of extinction. This shows for the first time that a single neuron is necessary for extinction. Finally, we have also established that the memory for extinction training can be extended using two different techniques: cooling and submersion. We postulate that the reason extinction could be extended is that interfering events, resulting in new learning, are the cause for forgetting (Sangha et al., 2003a). By extending the memory for extinction, we support the hypothesis that extinction is an active process, not a passive one. It also suggests that spontaneous recovery itself is not a passive process and may represent an inhibition of extinction expression.

Extinction is not forgetting, nor is it simply a case of unlearning. Rather, extinction involves the formation of a new memory that coexists along with the original memory. The data presented here are consistent with the hypothesis that, during extinction, a new associative memory is being formed, specifically an association between the behavior and the absence of reinforcement. In addition, the data support the view that, shortly after extinction training, there is a critical period in which protein synthesis and gene transcription are required for its induction. This is consistent with other studies investigating extinction in other learning paradigms (Berman and Dudai, 2001; Vianna et al., 2001, 2003). For example, Vianna et al. (2003) demonstrated that extinction of a one-trial step-down inhibitory avoidance task requires gene transcription and protein synthesis in the CA1 region of the rat hippocampus during the first set of extinction trials. Whereas their study applied the inhibitors $15 \mathrm{~min}$ before extinction training and our study administered them immediately after extinction training, both procedures disrupted memory formation for extinction. Vianna et al. (2003) also demonstrated that the inhibitors had no effect on memory formation if administered 1 or $3 \mathrm{hr}$ after the first set of extinction trials. Our finding that cooling can extend the memory for extinction training if applied $1 \mathrm{hr}$ after extinction training are consistent with Vianna et al. (2003), because the memory for extinction training was clearly not vulnerable to cooling at this later time point.

It seems that the memory for extinction training masks or covers up the memory for operant conditioning. However, be- 
cause inhibitory associations (i.e., those that develop during extinction) are generally more labile or subject to "easier" disruption by "interfering events" than are excitatory associations (i.e., those that develop during operant conditioning), they are lost with the passage of time (spontaneous recovery) or a shift in context (renewal) (Pavlov, 1927; Konorski, 1948; Bouton, 1993; Myers and Davis, 2002). For this reason, we observed memory for extinction at $2 \mathrm{hr}$ and memory for operant conditioning at $24 \mathrm{hr}$ (Figs. 2, 6A). To our knowledge, the data presented here are the first to demonstrate the phenomenon of spontaneous recovery in the Lymnaea model system.

Several laboratories are in search for the neural mechanisms underlying extinction. The problems that many of these laboratories face are that the excitatory and inhibitory associations under investigation may be orchestrated by different brain structures, different populations of cells within a given structure, or different types of molecules within individual cells (Davis and Myers, 2002). It has been suggested recently that extinction most likely occurs by an intracellular suppression of the memory trace, not by an intercellular mechanism (Schwaerzel et al., 2002). However, this study, performed in Drosophila, could not definitively locate the effects of extinction to one particular cell because they manipulated between one-fourth and one-third of the 2500 Kenyon cells that make up a single mushroom body. In contrast, we were able to demonstrate that one single cell (RPeD1) is necessary for memory formation of extinction, which, to our knowledge, has not been demonstrated in any other model system to date. Specifically, we showed that it is the soma of this particular cell that is critical. By ablating the soma of RPeD1 (and thus removing the nucleus) we are preventing any new RNA synthesis from occurring in this cell. However, this procedure leaves behind a fully functional neurite, thus allowing local protein synthesis to occur (Spencer et al., 2000). Therefore, although protein synthesis is necessary in the formation of a memory for extinction, as was seen in the cooling and anisomycin experiments, it is not sufficient. These data also imply that mRNA synthesis in $\mathrm{RPeD} 1$ is necessary for the formation of long-lasting memories of both extinction and of operant conditioning. This is not to say that $\mathrm{RPeD} 1$ is the only neuron in the respiratory network in which such changes occur (i.e., that these changes are sufficient), but only that the changes within RPeD1 are necessary for memory consolidation. Whether or not both memories involve the same cascade of events or differing ones remains to be determined. One possibility is that RPeD1 could act as a "trigger" cell for both operant conditioning and extinction acquisition and another cell downstream that is still part of the aerial respiratory network acts as a "storage" cell. This idea of trigger and storage cells has been applied to memory acquisition and storage in fear conditioning and cerebellar motor learning (Medina et al., 2002). In this model, the role of the trigger cell is in the initiation of learning whereas the storage cells show certain biochemical changes induced by conditioning. We have shown previously that $\mathrm{RPeD} 1$ is required for the consolidation of new LTMs of operant conditioning (Scheibenstock et al., 2002) and, we show here its requirement in inducing extinction, thus implicating $\mathrm{RPeD} 1$ as an attractive candidate for a trigger cell. In Lymnaea, it has yet to be determined whether memory is stored in just one cell or is distributed within the aerial respiratory network.

We were able to extend the persistence of extinction by cooling or preventing the occurrence of aerial respiratory behavior. Although these data are consistent with the hypothesis that extinction is learning and remembering something new, they are also important in their own right. Whereas extinction has been used therapeutically in the treatment of some behavioral disorders, its positive effects too often wane quickly. Thus, because we have shown that there are means of extending persistence of extinction, it may be possible to develop "postextinction training" strategies that will promote more lasting therapeutic effects. It is possible that these effects are specific to operant conditioning in Lymnaea and may not generalize to all extinction learning. Thus, more experimentation is needed to find other means of extending the memory of extinction and the mechanisms behind it.

\section{References}

Berman DE, Dudai Y (2001) Memory extinction, learning anew, and learning the new: dissociations in the molecular machinery of learning in cortex. Science 291:2417-2419.

Bouton ME (1993) Context, time and memory retrieval in the interference paradigms of Pavlovian conditioning. Psychol Bull 114:80-99.

Cartford MC, Gohl EB, Singson M, Lavond DG (1997) The effects of reversible inactivation of the red nucleus on learning-related and auditoryevoked unit activity in the pontine nuclei of classically conditioned rabbits. Learn Mem 3:519-531.

Davis HP, Squire LR (1984) Protein synthesis and memory: a review. Psychol Bull 96:518-559.

Davis M, Myers KM (2002) The role of glutamate and gammaaminobutyric acid in fear extinction: clinical implications for exposure therapy. Biol Psychiatry 52:998-1007.

Feng Z, Klumperman J, Lukowiak K, Syed N (1997) In vitro synaptogenesis between somata of identified Lymnaea neurons requires protein synthesis but not extrinsic growth factors or substrate adhesion molecules. J Neurosci 17:7839-7849.

Flood JF, Jarvik ME, Bennett EL, Orme AE, Rosenzweig MR (1977) Protein synthesis inhibition and memory for pole jump active avoidance and extinction. Pharmacol Biochem Behav 7:71-77.

Glass GV, Hopkins KD (1996) Statistical methods in education and psychology, Ed 3. Needham Heights, MA: Allyn and Bacon.

Hamakawa T, Woodin MA, Bjorgum MC, Painter SD, Takasaki M, Lukowiak K, Nagle GT, Syed NI (1999) Excitatory synaptogenesis between identified Lymnaea neurons requires extrinsic trophic factors and is mediated by receptor tyrosine kinases. J Neurosci 19:9306-9312.

Haney J, Lukowiak K (2001) Context learning and the effect of context on memory retrieval in Lymnaea. Learn Mem 8:35-43.

Konorski J (1948) Conditioned reflexes and neuronal organization. London: Cambridge UP.

Lattal KM, Abel T (2001) Different requirements for protein synthesis in acquisition and extinction of spatial preferences and context-evoked fear. J Neurosci 21:5773-5780.

Lukowiak K, Ringseis E, Spencer G, Wildering W, Syed N (1996) Operant conditioning of aerial respiratory behaviour in Lymnaea stagnalis. J Exp Biol 199:683-691.

Lukowiak K, Cotter R, Westley J, Ringseis E, Spencer G, Syed N (1998) Long term memory of an operantly conditioned respiratory behaviour in Lymnaea stagnalis. J Exp Biol 201:877-882

Lukowiak K, Adatia A, Krygier D, Syed N (2000) Operant conditioning in Lymnaea: evidence for intermediate and long-term memory. Learn Mem 7:140-150.

Lukowiak K, Sangha S, McComb C, Varshay N, Rosenegger D, Sadamoto H, Scheibenstock A (2003) Associative learning, long-term memory, and the assignment of 'marks' in the pond snail, Lymnaea. J Exp Biol 206:2097-2103.

McComb C, Sangha S, Qadry S, Yue J, Scheibenstock A, Lukowiak K (2002) Context extinction and associative learning in Lymnaea. Neurobiol Learn Mem 78:23-34.

McGaugh J (2000) Memory, a century of consolidation. Science 287:248-251.

Medina JF, Repa JC, Mauk MD, LeDoux JE (2002) Parallels between cerebellum- and amygdala-dependent conditioning. Nat Rev Neurosci 3:122-131.

Menzel R, Manz G, Menzel R, Greggers U (2001) Massed and spaced learning in honeybees: the role of CS, US, the intertribal interval, and the test interval. Learn Mem 8:198-208.

Morrison GE, van der Kooy D (1997) Cooling before associative condition- 
ing blocks memory retrieval, but cooling after conditioning blocks memory retention in Caenorhabditis elegans. Behav Neurosci 111:564-578.

Myers KM, Davis M (2002) Behavioral and neural analysis of extinction. Neuron 36:567-584.

Pavlov IP (1927) Conditioned reflexes. London: Oxford UP.

Rankin CH (2000) Context conditioning in habituation in the nematode Caenorhabditis elegans. Behav Neurosci 114:496-505.

Richards WG, Farley J, Alkon DL (1984) Extinction of associative learning in Hermissenda: behavior and neural correlates. Behav Brain Res 14:161-170.

Rosenzweig M, Bennett E, Colombo P, Lee D, Serrano P (1993) Short-term, intermediate term and long term memories. Behav Brain Res 57:193-198.

Sangha S, McComb C, Scheibenstock A, Johannes C, Lukowiak K (2002) The effects of continuous versus partial reinforcement schedules on associative learning, memory and extinction in Lymnaea stagnalis. J Exp Biol 205:1171-1178

Sangha S, McComb C, Lukowiak K (2003a) Forgetting and the extension of memory in Lymnaea. J Exp Biol 206:71-77.

Sangha S, Morrow R, Smyth K, Cooke R, Lukowiak K (2003b) Cooling blocks ITM and LTM formation and preserves memory. Neurobiol Learn Mem 80:130-139.

Sangha S, Scheibenstock A, Lukowiak K (2003c) Reconsolidation of a longterm memory in Lymnaea requires new protein and RNA synthesis and the soma of right pedal dorsal 1. J Neurosci 23:8034-8040.

Sangha S, Scheibenstock A, McComb C, Lukowiak K (2003d) Intermediate and long-term memories of associative learning are differentially affected by transcription vs. translation blockers in Lymnaea. J Exp Biol 206:1605-1613.

Scheibenstock A, Krygier D, Haque Z, Syed N, Lukowiak K (2002) The soma of RPeD1 must be present for LTM formation of associative learning in Lymnaea. J Neurophysiol 88:1584-1591.

Schwaerzel M, Heisenberg M, Zars T (2002) Extinction antagonizes olfactory memory at the subcellular level. Neuron 35:951-960.

Sekiguchi T, Yamada A, Suzuki H (1997) Reactivation-dependent changes in memory states in the terrestrial slug Limax flavus. Learn Mem 4:356-364.

Spencer G, Syed N, Lukowiak K (1999) Neural changes after operant conditioning of the aerial respiratory behavior in Lymnaea stagnalis. J Neurosci 19:1836-1843.

Spencer G, Syed N, van Kesteren E, Lukowiak K, Geraerts WPM, van Minnen J (2000) Synthesis and functional integration of a neurotransmitter receptor in isolated axons. J Neurobiol 44:72-81.

Spencer G, Kazmi M, Syed N, Lukowiak K (2002) Changes in the activity of a central pattern generator neuron following the reinforcement of an operantly conditioned behavior in Lymnaea. J Neurophysiol 88:1915-1923.

Syed NI, Bulloch AGM, Lukowiak K (1990) In vitro reconstruction of the respiratory central pattern generator of the mollusk Lymnaea. Science 250:282-285.

Syed NI, Ridgway R, Lukowiak K, Bulloch AGM (1992) Transplantation and functional integration of an identified respiratory interneuron in Lymnaea stagnalis. Neuron 8:767-774.

van Minnen J, Bergman E, Van Kesteren R, Smit A, Geraerts W, Lukowiak K, Hasan S, Syed N (1997) De novo protein synthesis in isolated axons. Neuroscience 80:1-7.

Vianna MR, Szapiro G, McGaugh JL, Medina JH, Izquierdo I (2001) Retrieval of memory for fear-motivated training initiates extinction requiring protein synthesis in the rat hippocampus. Proc Natl Acad Sci USA 98:12251-12254.

Vianna MR, Igaz LM, Coitinho AS, Medina JH, Izquierdo I (2003) Memory extinction requires gene expression in rat hippocampus. Neurobiol Learn Mem 79:199-203.

Yamada A, Sekiguchi T, Suzuki H, Mizukami A (1992) Behavioral analysis of internal memory states using cooling-induced retrograde amnesia in Limax flavus. J Neurosci 12:729-735.

Zar JH (1999) Biostatistical analysis, Ed 3. Upper Saddle River, NJ: Prentice Hall. 